\title{
Vascular Protection in Patients with Diabetes Admitted for Vascular Surgery in a Canadian Tertiary Care Hospital: Pilot Study
}

\author{
Melanie Sunderland, Mandy De Jong, and Duane Bates
}

\begin{abstract}
Background: Patients with peripheral artery disease are 6 times as likely as healthy individuals to die of cardiovascular causes within 10 years after diagnosis. Combination therapy with a statin, an angiotensinconverting enzyme (ACE) inhibitor or angiotensin II receptor blocker (ARB), and an antiplatelet agent is recommended to reduce cardiovascular events in patients with peripheral artery disease, especially those with concomitant diabetes mellitus and those who have undergone vascular surgery.
\end{abstract}

Objectives: The primary objective was to determine the proportion of patients with concurrent diabetes and peripheral artery disease who were receiving therapy with a statin, $\mathrm{ACE}$ inhibitor or $\mathrm{ARB}$, and antiplatelet agent (acetylsalicylic acid or clopidogrel) at the time of discharge after vascular surgery. The secondary objectives were to determine if target blood pressure was achieved and if smoking cessation therapy was offered and/or provided.

Methods: This pilot study was a retrospective, cross-sectional chart analysis. The health records database for Alberta Health Services was searched to identify patients with diabetes who underwent vascular surgery at the Foothills Hospital in Calgary with discharge between January 1 and June 30, 2010. In addition to baseline demographic characteristics, blood pressure values at the time of admission and discharge were collected. Discharge medications, including cardiovascular medications such as statins, ACE inhibitor or ARB, and antiplatelet agents, were recorded. Descriptive analysis of the data was performed.

Results: Of the 42 patients for whom charts were obtained, 25 (60\%) had prescriptions for cardiovascular triple therapy (statin, ACE inhibitor or ARB, antiplatelet agent). Just over half of the patients (23 [55\%]) had achieved target blood pressure $(<130 / 80 \mathrm{~mm} \mathrm{Hg})$ at the time of discharge. Of the 14 current smokers, 9 (64\%) had documented evidence in the chart that smoking cessation counselling was offered and/or drug therapy was provided.

Conclusion: Only about half of the patients in this study were receiving cardiovascular triple therapy, which suggests that many patients were not receiving optimal vascular protection. A larger study is needed to review prescribing patterns for patients with peripheral artery disease.

Keywords: peripheral artery disease, diabetes mellitus, vascular protection

Can J Hosp Pharm. 2013;66(4):227-32

\section{RÉSUMÉ}

Contexte : Les patients atteints d'une maladie artérielle périphérique ont un risque six fois plus élevé de mourir d'une maladie cardiovasculaire dans les 10 ans suivant le diagnostic que les personnes non atteintes d'une telle maladie artérielle. Les traitements associant une statine, un inhibiteur de l'enzyme de conversion de l'angiotensine (ECA) ou un antagoniste des récepteurs de l'angiotensine II (ARA), et un antiplaquettaire sont recommandés pour réduire le risque d'événements cardiovasculaires chez les patients atteints d'une maladie artérielle périphérique, particulièrement ceux présentant un diabète sucré concomitant ou ayant subi une chirurgie vasculaire.

Objectifs : Le principal objectif était de déterminer la proportion de patients présentant simultanément un diabète et une maladie artérielle périphérique qui recevaient un traitement associant une statine, un inhibiteur de l'ECA ou un ARA, et un antiplaquettaire (acide acétylsalicylique ou clopidogrel) au moment de leur congé de l'hôpital après une chirurgie vasculaire. Les objectifs secondaires étaient de déterminer si les chiffres tensionnels ciblés ont été atteints et si un traitement de cessation tabagique a été offert ou prodigué.

Méthodes : Il s'agit d'une étude pilote menée au moyen de l'analyse transversale rétrospective de dossiers médicaux. Une recherche a été effectuée dans la base de données des dossiers médicaux des Services de santé de l'Alberta pour recenser les patients atteints de diabète qui avaient subi une chirurgie vasculaire à l'Hôpital Foothills de Calgary et reçu leur congé entre le $1^{\text {er }}$ janvier et le 30 juin 2010. Les données démographiques de base ont été recueillies, de même que les chiffres tensionnels au moment de l'hospitalisation et du congé des patients. Les médicaments prescrits au congé du patient, dont les agents cardiovasculaires comme les statines, les inhibiteurs de l'ECA ou les ARA, et les antiplaquettaires, ont été relevés. Une analyse descriptive des données a été effectuée.

Résultats : Des 42 patients dont les dossiers médicaux ont été obtenus, 25 $(60 \%)$ avaient reçu une prescription pour une trithérapie cardiovasculaire (statine, inhibiteur de l'ECA ou ARA, antiplaquettaire). Un peu plus de la moitié des patients (23 [55\%]) avaient atteint les chiffres tensionnels ciblés (< 130/80 mm Hg) au moment de leur congé de l'hôpital. Selon les dossiers médicaux, des 14 fumeurs, 9 (64\%) avaient eu une consultation ou reçu une pharmacothérapie pour la cessation tabagique.

Conclusion : Environ seulement la moitié des patients de cette étude avaient reçu une trithérapie cardiovasculaire, ce qui suggère que plusieurs patients n'avaient pas reçu une prophylaxie vasculaire optimale. Une étude de plus grande envergure est nécessaire pour examiner les habitudes de prescription chez les patients atteints d'une maladie artérielle périphérique.

Mots clés : maladie artérielle périphérique, diabète sucré, protection vasculaire

[Traduction par l'éditeur] 


\section{INTRODUCTION}

$\mathrm{P}$ eripheral vascular disease is a term for diseases in which blood vessels are blocked or restricted. The most common type of peripheral vascular disease is peripheral artery disease (PAD), which is usually caused by atherosclerosis. People at the highest risk for PAD include smokers, those with diabetes mellitus, and those with previous coronary or cerebrovascular disease. ${ }^{1}$ Approximately $20 \%$ to $30 \%$ of patients with diabetes also have PAD. ${ }^{2}$ Patients with evidence of PAD are 6 times as likely to die of cardiovascular causes within 10 years after diagnosis as healthy individuals without PAD. ${ }^{3}$ The literature on appropriate medical treatment and vascular protection for patients with $\mathrm{PAD}$ is scant in comparison to the corresponding literature for patients with coronary artery disease. ${ }^{2}$

The guidelines of the Canadian Diabetes Association ${ }^{4}$ and the Canadian Cardiovascular Society ${ }^{5-7}$ have suggested that patients with peripheral vascular disease would benefit from therapy with a statin, angiotensin-converting enzyme (ACE) inhibitor or angiotensin receptor blocker (ARB), and acetylsalicylic acid (ASA). ${ }^{4-7}$ If the patient is unable to tolerate ASA, consideration of clopidogrel therapy is recommended. ${ }^{6}$ The benefits of these drugs are believed to be independent and cumulative, with a possible reduction in the risk of future events of $75 \%$ when they are used together. ${ }^{7}$ Likewise, the Canadian Cardiovascular Society's 2005 guidelines for $\mathrm{PAD}^{7}$ suggested that smoking cessation leads to significant improvement in walking distance and reduces the risk of cardiovascular events. The guidelines go so far as to say that smoking cessation is likely more effective at preventing morbidity and mortality than any drug therapy. Finally, the guidelines suggest that all patients with peripheral vascular disease and diabetes target blood pressure less than 130/80 mm Hg.

The use of these drugs for PAD is supported by a variety of trial results. The Heart Protection Study Collaborative Group completed a prospective, randomized trial, with a subgroup analysis of 6748 adults with PAD, to determine the effects of simvastatin on cardiovascular events. Participants were assigned to receive simvastatin $40 \mathrm{mg}$ daily or placebo. The absolute reduction in first major vascular events for the patients with PAD in the simvastatin group was $6.3 \% .{ }^{8}$ Patients with PAD who were included in a subgroup analysis of the Heart Outcomes Prevention Evaluation (HOPE) study were analyzed to determine the effect of ramipril on major cardiovascular events. Patients were randomly assigned to treatment with either ramipril or placebo and were followed for 4.5 years. The absolute risk reduction for major cardiovascular events in the ramipril group was $5.7 \%$. ${ }^{9}$

In contrast, as described by Feldman and Moussa, ${ }^{10}$ a meta-analysis of 18 trials investigating the effect of ASA on cardiovascular events in patients with isolated PAD revealed that treatment with ASA did not significantly reduce the combined end point of cardiovascular events (relative risk 0.75, 95\% confidence interval [CI] 0.48-1.18). However, ASA therapy resulted in a significant reduction in the incidence of nonfatal stroke (relative risk $0.64,95 \%$ CI $0.42-0.99$ ). The authors concluded that the meta-analysis may have been underpowered to show a $25 \%$ risk reduction in all cardiovascular events. Some clinicians have suggested that a combination of clopidogrel and ASA or clopidogrel alone may be more effective than ASA alone. ${ }^{10}$

In practice, there is evidence to suggest the underuse of these evidence-based therapies. North American and European studies from the 1990s and early 2000s suggest that less than $50 \%$ of patients received appropriate vascular protection..$^{11-14}$ In the most recent and largest study to date regarding appropriate vascular protection in $\mathrm{PAD}$, prescribing rates were below $40 \%$ for statins, ACE inhibitor or ARB, and ASA (considered individually), despite the evidence suggesting that most patients with PAD would benefit from these therapies. ${ }^{13}$

The study reported here was undertaken to investigate pharmacotherapy provided to patients with concurrent diabetes and PAD and the prescribing trends for cardiovascular agents used in this population. More specifically, the purpose of the study was to determine the proportion of patients receiving appropriate vascular protection on discharge after vascular surgery in a Canadian tertiary care hospital.

\section{METHODS}

This pilot study was a cross-sectional retrospective chart analysis. The primary literature on peripheral vascular disease and its medical treatment was searched using the keywords "peripheral artery disease", "peripheral vascular disease", "diabetes", "vascular protection", "best medical management", "antiplatelet agent", "ACE-I", "ARB", "cholesterol”, "statins", "aspirin", "clopidogrel", and "vascular surgery". A computerized search of the Alberta Health Services health records database was carried out to identify patients with diabetes who had received care on a 40-bed vascular surgery unit following vascular surgery at the Foothills Hospital and who had been discharged between January 1 and June 30, 2010. All of these patients had had a clinical pharmacist assigned to their care, and the attending physician for each patient was a vascular surgeon. The patients were identified in the health records database using the vascular surgeons' names and "diabetes" as keywords.

Patients who met the following criteria were included in the study: age 18 years or older, diagnosis of type 1 or type 2 diabetes, and vascular surgery at the study hospital. Each patient underwent one of the following types of surgery: carotid endarterectomy, endovascular abdominal aortic aneurysm repair, open abdominal aortic aneurysm repair, 
amputation due to peripheral vascular disease, peripheral artery repair, peripheral vessel extraction, or peripheral vessel bypass. Patients meeting the following criteria were excluded: pregnant women, patients with diabetes who underwent vascular surgery but were not admitted to the hospital's vascular surgery unit, and patients who died in hospital. Patients not admitted to the vascular surgery unit were excluded because they did not have clinical pharmacist coverage.

The primary objective of the study was to determine the proportion of patients with both diabetes and peripheral vascular disease who were discharged from the vascular surgery unit with prescriptions for statin, ACE inhibitor or ARB therapy, and/or antiplatelet agent (ASA or clopidogrel). The study also had 2 secondary objectives: first, to determine if the blood pressure target of the 2008 Canadian Diabetes Association guidelines $(<130 / 80 \mathrm{~mm} \mathrm{Hg})^{4}$ was reached on the day of discharge and second, to determine the proportion of study patients who were current smokers who had been offered smoking cessation counselling and/or drug therapy during their admission or before admission to the hospital.

Data were collected retrospectively from patients' charts and were recorded on a standard data collection form. The data were gathered from the following information sources for each patient: demographic record, medication administration record, records of the electronic physician order entry system, preadmission internal medicine notes, and pharmacist's discharge education and planning notes. Baseline demographic data included age, sex, body mass index (BMI), comorbidities (specifically hypertension, dyslipidemia, coronary artery disease, cerebrovascular disease, end-stage kidney disease requiring dialysis, atrial fibrillation, and heart failure), and smoking status. Data for in-hospital deaths were also collected.

Discharge medications, including statins, ACE inhibitors or ARBs, and antiplatelet agents, were recorded. Additional information collected was the first blood pressure recorded on the day of admission and the last blood pressure recorded before discharge. Each blood pressure value was measured by a registered nurse using an electronic or aneroid sphygmomanometer. Evidence of smoking cessation interventions during the hospital stay or at the preadmission clinic was collected (i.e., any chart documentation indicating that the patient had been encouraged to quit smoking, had been asked if he/she was interested in stopping smoking, had been advised of the risks of smoking, or had been offered counselling or smoking cessation medications).

\section{Statistical Analysis}

Descriptive analyses were performed on the data obtained. The estimate for the primary objective was provided as a percentage. Fisher's exact test was used to determine potential confounders for receipt of triple therapy. The secondary objective regarding smoking cessation was reported as a percentage, and blood pressure results were given as means with corresponding standard deviations, as well as the percentage of patients reaching blood pressure targets.

\section{RESULTS}

A total of 44 charts were reviewed. Of these 44 potential participants, 2 died before discharge and were excluded from analysis. More than two-thirds of the patients were men, and the mean age was 67 years (see Table 1). The patients had a variety of comorbidities, with large proportions having known coronary artery disease, hypertension, or dyslipidemia (Table 1). A large majority of the patients (33 [79\%]) were previous or current smokers.

Twenty-five patients (60\%) were receiving triple vascular protection with a statin, ACE inhibitor or ARB, and antiplatelet agent on discharge (Table 2). Of the 4 patients with end-stage renal disease requiring dialysis, 2 were not receiving an ACE inhibitor or ARB. Eleven (46\%) of the 24 patients with $\mathrm{PAD}$ alone (no comorbidities) were receiving triple therapy, whereas $14(78 \%)$ of the 18 patients with both coronary artery disease and PAD were receiving triple therapy. Fisher's exact test was performed to identify covariates for receipt of triple therapy: age, sex, BMI, and history of coronary artery disease, cerebrovascular disease, heart failure, hypertension, and dyslipidemia. Coronary artery disease was the only factor that was of borderline significance $(p=0.057)$.

Twenty-three (55\%) of the patients achieved target blood

\section{Table 1. Baseline Demographic and Clinical Characteristics}

\begin{tabular}{lrr} 
Characteristic & $\begin{array}{r}\text { No. (\%) of Patients* } \\
(\boldsymbol{n}=\mathbf{4 2})\end{array}$ \\
\hline Sex, no. (\%) male & 30 & $(71)$ \\
\hline Age (years) & $67 \pm$ & 12.6 \\
Mean \pm SD & 3 & $(7)$ \\
$<50$ years & 15 & $(36)$ \\
$50-64$ years & 17 & $(40)$ \\
$65-80$ years & 7 & $(17)$ \\
$>80$ years & $28.0 \pm 5.8$ \\
\hline Body mass index $\mathbf{( k g / \mathbf { m } ^ { 2 } )}$ & 34 & $(81)$ \\
\hline Comorbidities & 27 & $(64)$ \\
Hypertension & 18 & $(43)$ \\
Dyslipidemia & 7 & $(17)$ \\
Coronary artery disease & 6 & $(14)$ \\
Atrial fibrillation & 5 & $(12)$ \\
Cerebrovascular disease & 4 & $(10)$ \\
Heart failure & & \\
End-stage kidney disease requiring dialysis & 14 & $(33)$ \\
Smoking history & 19 & $(45)$ \\
Current smoker & 33 & $(79)$ \\
Past smoker & &
\end{tabular}

*Except where indicated otherwise. 
Table 2. Prescribing Rates for Patients

\begin{tabular}{|c|c|c|}
\hline Drug & $\begin{array}{l}\text { No. }(\%) \text { of } \\
\qquad(n=\end{array}$ & $\begin{array}{l}\text { f Patients* } \\
\text { 42) }\end{array}$ \\
\hline Statins & 31 & (74) \\
\hline ARB or ACE inhibitor & & \\
\hline ARB & 9 & (21) \\
\hline ACE inhibitor & 23 & (55) \\
\hline Dual therapy (ARB + ACE inhibitor) & 0 & \\
\hline Antiplatelet agents & & \\
\hline ASA monotherapy & 26 & (62) \\
\hline Clopidogrel monotherapy & 2 & (5) \\
\hline Dual therapy (ASA + clopidogrel) & 9 & (21) \\
\hline $\begin{array}{l}\text { Triple therapy (antiplatelet + } \\
\text { statin + ACE inhibitor/ARB) }\end{array}$ & 25 & (60) \\
\hline $\begin{array}{l}\mathrm{ACE}=\text { angiotensin-converting enzyr } \\
\text { receptor blocker, } \mathrm{ASA}=\text { acetylsalicyl }\end{array}$ & $\begin{array}{l}A R B=\text { angi } \\
\text { id. }\end{array}$ & otensin \\
\hline Table 3. Blood Pressure & & \\
\hline Variable & $\begin{array}{r}\text { No. }(\%) \text { o } \\
\text { or Mea }\end{array}$ & $\begin{array}{l}f \text { Patients } \\
\text { an } \pm \text { SD }\end{array}$ \\
\hline At target on discharge & 23 & $(55)$ \\
\hline Blood pressure values $(\mathrm{mm} \mathrm{Hg})$ & & \\
\hline Systolic on admission & 130.6 & \pm 21.9 \\
\hline Diastolic on admission & 72.2 & \pm 12.2 \\
\hline Systolic on discharge & 129.4 & \pm 20.2 \\
\hline Diastolic on discharge & 69.0 & \pm 11.8 \\
\hline
\end{tabular}

pressure $(<130 / 80 \mathrm{~mm} \mathrm{Hg}$ ) by the time of discharge (Table 3). All patients had documentation of current smoking status in the chart. Of the 14 current smokers, 9 (64\%) had documented evidence that smoking cessation counselling and/or drug therapy had been offered. There was no chart documentation regarding whether the patients had accepted counselling or drug therapy or the specific type of counselling or drug therapy offered.

\section{DISCUSSION}

The finding that $60 \%$ of patients were receiving triple therapy at the time of discharge is a positive and encouraging result, although there is still room for improvement. Given the strong evidence suggesting that patients with PAD are at high risk for cardiovascular events, these patients would generally benefit from triple therapy. ${ }^{2-10}$ Prescribing rates in the current study appeared to be higher than those reported in another Canadian study, from Hamilton, Ontario, which was performed in the early 2000s. The analysis in the Hamilton study involved patients with PAD admitted to hospital from January 2001 to January $2002(n=217)$. The primary reason for admission was peripheral artery bypass surgery (67\%). Of these patients, $79 \%$ were current smokers or had a prior smoking history, and $45 \%$ had undergone prior peripheral artery bypass surgery, amputation, or carotid endarterectomy.
Most of the patients had established coronary artery disease, cerebrovascular disease, or at least 2 cardiovascular risk factors. At the time of discharge, $31 \%$ were receiving statins, $52 \%$ ACE inhibitors, and $84 \%$ antiplatelet or anticoagulant agents. ${ }^{15}$

The higher rates of therapy reported in the current study, relative to the Hamilton study, may be due to an increase in medical literature suggesting that statins, ACE inhibitor or $A R B$, and antiplatelet agents are important for secondary prevention of cardiovascular events. In particular, the publication of Canadian PAD guidelines ${ }^{7}$ in 2005 may have had a positive impact on prescribing trends. In contrast, better medical management of PAD than what has previously been reported in the literature could also be related to the multidisciplinary environment on the vascular surgery unit in the study hospital, where a pharmacist was part of the care team.

The most recent and largest study to date regarding PAD prescribing trends and appropriate vascular protection reviewed data for 7458 patients with PAD who were treated from 1999 to 2004 in the United States. Statin therapy was prescribed for only $30 \%$ of the patients, ACE inhibitor or ARB therapy for $24 \%$, and ASA for $36 \% \cdot{ }^{13}$ In the current study, $60 \%$ of the patients were receiving triple vascular protection. Although the results from the large US study cannot be directly compared with the findings of the current small retrospective chart review, the results suggest that we have reason to be optimistic.

Despite an increase over time in the prescribing of vascular protection in patients with $\mathrm{PAD}$, the proportion of patients in the current study who were receiving best medical vascular protection (i.e., triple therapy) for isolated PAD was less than among patients with both coronary artery disease and PAD (46\% versus 78\%), a pattern that has been noted in previous literature., ${ }^{2,11-15}$ For example, in one study, lipid-lowering therapy was prescribed for $70 \%$ of patients with both $\mathrm{PAD}$ and coronary artery disease, but for only $35 \%$ those with isolated PAD. ${ }^{12}$ This may reflect a lack of randomized controlled trials in the PAD population. Educating and informing prescribers about PAD and its cardiovascular risk may help to ensure that patients receive appropriate therapy. Implementing protocols and policies and applying quality assurance programs can help to address these prescribing deficiencies by ensuring a systematic approach to the review and assessment of patients' medications. ${ }^{16}$

Of the various vascular protection agents, antiplatelet agents were prescribed most frequently. One possible reason for higher prescribing of antiplatelet agents may be physicians' greater knowledge about these agents relative to other cardiovascular agents. Some patients were not receiving an ACE inhibitor or ARB. It is difficult to understand why so many patients were not receiving one of these drugs, but possible reasons include contraindications or intolerances such as hyperkalemia and renal failure. Notably, the management of 
hypertension in patients with both diabetes and PAD is important for minimizing cardiovascular risks, but if a patient cannot take an ACE inhibitor or ARB, other agents may be used.?

There is evidence to suggest that smoking cessation is the most important intervention for patients with PAD. It helps directly with PAD symptoms and reduces the risk of cardiac events. ${ }^{7}$ In the current study, $64 \%$ of the patients who were current smokers had evidence of smoking cessation discussions or interventions with health care professionals. Although this retrospective chart analysis could not capture all details of interventions related to smoking cessation, this behaviour change is a great step forward.

This study had several limitations, including small sample size, retrospective design, and potentially incomplete chart documentation, all of which limit the generalizability and interpretation of the results. Because of the small sample size, the study may not have had enough power to detect statistically significant covariates for triple therapy. Given the retrospective design, it is unclear whether patients had contraindications to medications that prevented them from receiving triple therapy. Two of the patients not receiving ACE inhibitor or ARB therapy may have not been receiving these drugs because of end-stage renal disease requiring dialysis, but this specific reason was not documented in the chart. Some additional patients may have received smoking cessation counselling without documentation of the intervention. Also, some patients may not have had target blood pressure at the time of discharge secondary to the physiological stress of recent vascular surgery; as such, discharge blood pressure may not have been a true reflection of their blood pressure control. Likewise, recording a single blood pressure value on discharge does not provide a global picture of a patient's blood pressure.

\section{CONCLUSIONS}

This study can be considered a pilot study evaluating prescribing trends in patients with concurrent diabetes and PAD. The data revealed a lack of appropriate prescribing of vascular protection for patients with $\mathrm{PAD}$ relative to those with both coronary artery disease and PAD. A much larger sample size is needed to comprehensively evaluate the medical management of patients with PAD. The results of this pilot trial may help pharmacists and physicians working in vascular surgery to develop protocols and implement specific quality improvement initiatives and thereby to help ensure that patients are receiving optimal medical management of their PAD.

\section{References}

1. Peripheral artery disease - legs. In: A.D.A.M. medical encyclopedia [Internet]. Atlanta (GA): A.D.A.M. Inc; [last reviewed 2012 May 14; cited 2012 Aug 15]. Available from: www.ncbi.nlm.nih.gov/pubmedhealth/ PMH0001223/
2. Burns P, Lima E, Bradbury AW. Second best medical therapy. Eur J Vasc Endovasc Surg. 2002;24(5):400-4.

3. Hackam DG, Goodman SG, Anand SS. Management of risk in peripheral artery disease: recent therapeutic advances. Am Heart J. 2005; 150(1):35-40.

4. Canadian Diabetes Association Clinical Practice Guidelines Expert Committee. Vascular protection for people with diabetes. In: Canadian Diabetes Association 2008 clinical practice guidelines for the prevention and management of diabetes in Canada. Can J Diabetes. 2008;32 Suppl 1:S102-6.

5. Genest J, McPherson R, Frohlich J, Anderson T, Campbell N, Carpentier A, et al. 2009 Canadian Cardiovascular Society/Canadian guidelines for the diagnosis and treatment of dyslipidemia and prevention of cardiovascular disease in the adult-2009 recommendations. Can J Cardiol. 2009;25(10):567-79.

6. Bell AD, Roussin A, Cartier R, Chan WS, Douketis JD, Gupta A, et al.; Canadian Cardiovascular Society. The use of antiplatelet therapy in the outpatient setting: Canadian Cardiovascular Society guidelines. Can J Cardiol. 2011;27 Suppl A:S1-59.

7. Canadian Cardiovascular Society. Canadian guidelines for the management of peripheral arterial disease (PAD). Can J Cardiol. 2005;21(12): 997-1006.

8. Heart Protection Study Collaborative Group. Randomized trial of the effects of cholesterol-lowering with simvastatin on peripheral vascular and other major vascular outcomes in 20,536 people with peripheral arterial disease and other high-risk conditions. J Vasc Surg. 2007;45(4):645-54; discussion 653-4.

9. Ostergren J, Sleight P, Dagenais G, Danisa K, Bosch J, Qilong Y, et al.; HOPE study investigators. Impact of ramipril in patients with evidence of clinical or subclinical peripheral arterial disease. Eur Heart J. 2004; 25(1):17-24.

10. Feldman DN, Moussa ID. Efficacy of aspirin for secondary prevention in patients with peripheral artery disease. Expert Rev Cardiovasc Ther. 2009;7(10):1203-7.

11. Bismuth J, Klitfod L, Sillesen H. The lack of cardiovascular risk factor management in patients with critical limb ischaemia. Eur J Vasc Endovasc Surg. 2001;21(2):143-6.

12. Khan S, Flather M, Mister R, Delahunty N, Fowkes G, Bradbury A, et al. Characteristics and treatments of patients with peripheral arterial disease referred to UK vascular clinics: results of a prospective registry. Eur J Vasc Endovasc Surg. 2007;33(4):442-50.

13. Pande RL, Perlstein TS, Beckman JA, Creager MA. Secondary prevention and mortality in peripheral artery disease. Circulation. 2011;124(1):17-23.

14. Anand SS, Kundi A, Eikelboom J, Yusuf S. Low rates of preventive practices in patients with peripheral vascular disease. Can J Cardiol. 1999;15(11):1259-63.

15. Kundhal KK, Chin SL, Harrison L, Nowacki B, Doobay B, Titley J, et al. Patterns of medical therapy in patients with peripheral artery disease in a tertiary care centre in Canada. Can J Cardiol. 2007;23(5):357-61.

16. Grindrod KA, Patel P, Martin JE. What interventions should pharmacists employ to impact health practitioners' prescribing practices? Ann Pharmacother. 2006;40(9):1546-57.

Melanie Sunderland, BSCPharm, ACPR, was, at the time this study was performed, with the Foothills Medical Centre, Alberta Health Services, Calgary, Alberta. She is now a student in the PharmD program at the University of British Columbia, Vancouver, British Columbia.

Mandy De Jong, BSP, MSC, is with the Foothills Medical Centre, Alberta Health Services, Calgary, Alberta.

Duane Bates, BSCPharm, ACPR, is with the Foothills Medical Centre, Alberta Health Services, Calgary, Alberta. 
Address correspondence to:

Melanie Sunderland

4140 West 10th Avenue

Vancouver BC V6R $2 \mathrm{H} 3$

e-mail: mas5@ualberta.ca

Competing interests: Duane Bates has received speaker's fees from Astra Zeneca and Calea, as well as for presentations at the Annual General Meeting of the Alberta Branch of the Canadian Society of Hospital Pharmacists (CSHP), the CSHP Professional Practice
Conference, and the CSHP Banff Conference. He has also received payment for preparation of a manuscript on aminoglycoside ototoxicity for the publication Drugs of Today. None declared for Melanie Sunderland or Mandy De Jong.

Acknowledgements

We thank Mary Ensom and Roxance Carr for their assistance with statistical analysis (Fisher's exact test).

\section{Membership Year 2013/2014 \\ (July 1, 2013 - June 30, 2014)}

Are you a member of the Canadian Society of Hospital Pharmacists?

CSHP has celebrated 66 years of inspiration and leadership among a rapidly growing network of over 3000 pharmacy colleagues. As a member of CSHP, you will have access to resources and opportunities that will enhance your career and help impact the direction of healthcare in Canada. Your participation in CSHP 2015, an initiative challenging all pharmacists to improve patient medication outcomes and safety through advancing pharmacy practice excellence by the year 2015 , is a prime example.

We invite you to reap the benefits of an affordable membership with CSHP. For more information, please visit www.cshp.ca.

Membership Enquiries: Please contact Membership Services

Tel.: (613) 736-9733 Ext. 222 Fax: (613) 736-5660 Email: membershipservices@cshp.ca 